\title{
Board 4: Curriculum on Diversity and Ethics: Impact in an Introductory Bioengineering Course
}

\section{Gunnarsson, Massachusetts Institute of Technology Camille Birch, University of Washington}

Camille Birch is a graduate of the Bioengineering and Computer Science departments at the University of Washington. She developed curriculum concerning the interplay of diversity and ethics for undergraduate engineering students at UW and is interested in the power of education to enact change in future generations of engineers. She currently works for Microsoft in the Bay Area.

\section{Dr. Dianne Grayce Hendricks, University of Washington}

Dr. Dianne Hendricks is a Lecturer in the Department of Human Centered Design \& Engineering and the Director of the Engineering Communication Program at the University of Washington. She designs and teaches courses involving universal design, technical communication, ethics, and diversity, equity and inclusion. She co-founded HuskyADAPT (Accessible Design and Play Technology), where she mentors UW students in design for local needs experts with disabilities. She also leads STEM outreach activities for the UW community and local K-12 students involving toy adaptation for children with disabilities. Dianne holds a PhD in Genetics from Duke University, and BS in Molecular Biology and BA in Psychology from the University of Texas at Austin. 


\section{Work in Progress: Curriculum on Diversity and Ethics: Impact in an Introductory Bioengineering Course}

Ethics and diversity are critical components of engineering training and practice, but most undergraduate engineering programs do not address these issues in-depth [1-3]. In this work-inprogress, we describe the design and implementation of a novel curriculum focused on the interplay of diversity and ethics.

We launched this curriculum through an honors section in a large introductory bioengineering course at the University of Washington. The creation of an honors section builds on our previous work, where we discussed curriculum design and pilot efforts of a short module in the introductory bioengineering course [4-5].

\section{Course Overview}

The introductory bioengineering course aims to provide broad exposure to several areas of research in bioengineering such as cancer diagnostics, medical device development, regenerative medicine, global health, and synthetic biology. The course emphasizes critical reading of scientific literature and technical writing, and broadly covers the engineering design process, creative problem-solving techniques, engineering ethics, social constraints, and other design principles.

The first offering of the honors section was a 2-credit add-on to the introductory bioengineering course. The honors section was comprised of 12 students who were concurrently enrolled in the large introductory bioengineering course (enrollment: 93 students total).

Our curriculum includes topics such as the importance of diversity and ethics competency in engineering; historic and current case studies of diversity-related ethical issues in bioengineering, and how historical perceptions and contexts still influence modern scientific thinking and engineering design; advocacy and representation of minorities in engineering; evidence supporting the value of inclusive teaching and diverse teams; and best practices for advocacy and representation of diverse peoples in engineering. The course schedule is shown in Appendix I.

The learning objectives include:

1. Summarize key case studies regarding diversity-related ethics in STEM.

2. Identify how cultural concepts of race, gender, sexuality and disability have shaped scientific thought (and vice versa) through history.

3. Critically evaluate literature regarding ethics and diversity in bioengineering.

4. Analyze how engineers handle implicit bias during research and design processes.

5. Propose approaches to promote ethics and diversity in engineering practice.

The honors students attended the same class sessions and completed all assignments as their nonhonors peers. In addition, the honors students attended a weekly two-hour discussion section and completed additional assignments including weekly readings, written reflections, and a final paper on a topic of their choice related to the role of diversity/diverse identities in engineering practice. Examples of topics chosen by students for the final paper are shown in Table I [5]. 


\section{Table I. Topics identified by students for final paper in honors section [5].}

- Impacts of science/research on marginalized groups, particularly AfricanAmericans, in the United States.

- Exploration of how modern cultural/societal perspectives on disability affect participation of people with disabilities in STEM.

- Examination of how various media forms enforce stereotypical roles of women, thus discouraging women from entering STEM fields.

- Evaluation of scientific attempts to classify sexual orientation based on neurophysiological findings and analysis of how this research influences our perceptions of gender and sexual identities.

- Exploring the ethical ramifications of artificial intelligence and the study of neural networks, particularly focusing on who will benefit/not benefit from this technology and potential negative consequences.

- Considering the role of women in computer science over time, particularly examining how computer science went from a female-dominated field to a maledominated field, with a focus on media portrayal, stereotyping, and institutional barriers.

\section{Student Impact and Assessment}

Throughout the course, instructor observations and informal feedback from students were overwhelmingly positive. At the end of the quarter, students were asked to reflect on two things that they learned in the honors section that they will use in the future in their personal life, education, and/or career.

In these reflections, several students mentioned the course's emphasis on ethics as a component of diversity, and vice versa. Most of the students stated that their design approach will be affected by their increased awareness of people with diverse needs and experiences. Excerpts from student reflections include:

"Another thing I learned a lot about in this class is ethics, especially in relation to what I might do with research in the future... it really got me thinking about how I would act in certain situations. I am now more aware of who should be involved in clinical trials and [their] rights."

"I believe the most important thing I've learned [is the] importance of having diversity in the engineering design process, especially when identifying a need. This was exemplified by... the fact that paraplegics and quadriplegics don't have walking as a [top] priority of theirs. In the future, I will make sure to take into account many different perspectives before pursuing any engineering design."

"I learned about the disconnect between engineers building technologies for disabled people and the disability community themselves. Along the way, I learned about the sensitivity of the language used to describe disabled people, 
such as the need to avoid implying that disabled people need to be 'fixed.' This... reminded me to be careful in identifying the need when I'm developing

engineering solutions in the future."

The end-of-course student evaluations were very positive. Students reported that they enjoyed the course, found the course content engaging, and appreciated the challenge of writing an indepth analysis of a topic of their choice. However, the students indicated very strongly that the amount of work was too heavy for a 2-credit add-on. We are thoughtfully considering this feedback as we develop an advanced course: "Science and Engineering for Social Justice" [6-7].

Representative excerpts from end-of-course evaluations include:

"Yes, it was my favourite class this quarter! It enabled me to approach concepts of diverse representation in STEM and bioethics in entirely new ways that will make me a better engineer."

"[The] honors section was one of the most interesting classes I have taken. The topics we discussed were thought-provoking and forced me to consider ideas that I have not thought about before."

"The Honors section of this class was very intellectually stimulating. We learned about aspects of bioengineering that I had never thought about before and most STEM classes do not discuss. It also challenged us to think about problems from multiple perspectives."

"I gained exposure to topics in bioengineering that I hadn't previously known much about, and I learned a lot about the nuanced and complicated diversity and ethics issues that are woven into scientific work. The Honors section was the most intellectually stimulating part of the course for me."

\section{Conclusions}

Here we present an initial examination of the impact of the first offering of our curriculum through a new honors section of the large introductory bioengineering course. Instructor observations and informal feedback from students were overwhelmingly positive. At the end of the quarter, students identified that the most important things they learned in the course were ethics and consideration of diverse audiences in the design process. Example curricular materials will be available at the conference.

\section{References}

1. National Academy of Engineering. (2008) "Changing the Conversation: Messages for Improving Public Understanding of Engineering." The National Academies Press, Washington, D.C

2. Hess, J.L. and Fore, G. (2017) "A Systematic Literature Review of US Engineering Ethics Interventions.” Science and Engineering Ethics. DOI: 10.1007/s11948-017-9910-6. 
3. Herkert, J.R. (2010) "Engineering ethics education in the USA: Content, pedagogy and curriculum.” European Journal of Engineering Education, 25:4, 303-313. DOI: $10.1080 / 03043790050200340$

4. C. Gunnarsson, C. Birch, and D.G. Hendricks. "Exploring the Interplay of Diversity and Ethics in an Introductory Bioengineering Course", Pacific Northwest Section Conference, American Society for Engineering Education, Seattle WA. (April 2017)

5. C. Birch, C. Gunnarsson, and D.G. Hendricks. "Work in Progress: Exploring the Interplay of Diversity and Ethics in an Introductory Bioengineering Course." American Society for Engineering Education Annual Conference, Salt Lake City, UT. (2018)

6. C. Gunnarsson, C. Birch, and D.G. Hendricks "Design and Implementation of an Engineering for Social Justice Curriculum.” Collaborative Network for Engineering and Computing Diversity (CoNECD) Annual Conference, Crystal City, VA. (2019)

7. C. Birch, C. Gunnarsson, and D.G. Hendricks. "Work in Progress: Science and Engineering for Social Justice: Curriculum Development and Student Impact", American Society for Engineering Education Annual Conference, Tampa, FL. (2019) 


\begin{tabular}{|c|c|c|}
\hline \multicolumn{3}{|c|}{ Appendix A. Course Schedule for Honors Section } \\
\hline Week & Topic & Assignment Due \\
\hline 1 & Introduction + Intro to Engineering/Design & $\begin{array}{l}\text { Pre-class survey } \\
\text { Classroom expectations }\end{array}$ \\
\hline 2 & History of Gender/Sex & $\begin{array}{l}\text { Research topics for } \\
\text { individual paper }\end{array}$ \\
\hline 3 & History of Race & $\begin{array}{l}\text { Individual paper: Topic } \\
\text { proposal }\end{array}$ \\
\hline 4 & History of Disability & $\begin{array}{l}\text { Individual paper: Annotated } \\
\text { bibliography }\end{array}$ \\
\hline 5 & $\begin{array}{l}\text { Designing for Diverse Populations // Universal Design } \\
\text { Debate: Should we "fix" people? }\end{array}$ & Preparation for debate \\
\hline 6 & Scientific Communication & Individual paper: First draft \\
\hline 7 & Peer Review & $\begin{array}{l}\text { Individual paper: Peer } \\
\text { review }\end{array}$ \\
\hline 8 & Designing Research & $\begin{array}{l}\text { Optional second draft for } \\
\text { more instructor feedback }\end{array}$ \\
\hline 9 & Representation in Engineering & \\
\hline 10 & Course Wrap-Up and Evaluations & Individual paper: Final draft \\
\hline
\end{tabular}

